\title{
Clival Chordoma: Endoscopic Bilateral Transmaxillary Approach
}

\section{A. Samy Youssef ${ }^{1}$ Alexander Yang ${ }^{2}$ Anne E. Getz ${ }^{3}$ Inoue Mizuho ${ }^{2}$ Mohamed Labib ${ }^{4}$}

1 Department of Neurosurgery and Otolaryngology, University of Colorado, Aurora, Colorado, United States

2 Department of Neurosurgery, University of Colorado, Aurora, Colorado, United States

${ }^{3}$ Department of Otolaryngology, University of Colorado, Aurora, Colorado, United States

${ }^{4}$ Department of Neurosurgery, Barrow Neurological Institute, St. Joseph's Hospital and Medical Center, Phoenix, Arizona, United States

J Neurol Surg B 2019;80(suppl S4):S371.

\begin{abstract}
Address for correspondence A. Samy Youssef, MD, PhD, Department of Neurosurgery and Otolaryngology, University of Colorado, Mail Stop C307, 12631 East 17th Avenue, Aurora, CO 80045, United States (e-mail: Samy.Youssef@UCDenver.edu).
\end{abstract}

\begin{abstract}
Keywords

- endoscopic endonasal

- chordoma

- clival

- transmaxillary

We present a case of a large clival chordoma in a 54-year-old female with a past medical history of Turner's syndrome and a 1.5-year history of nasal congestion. The tumor was extending in the nasopharynx to both pterygopalatine fossae. An expanded endoscopic endonasal approach was selected. Stereotactic navigation was utilized. Bilateral transmaxillary approach with ethmoidectomy was performed, and a transclival corridor to the deepest portion of the tumor was created. The tumor was successfully dissected off the medial walls of the cavernous sinuses. Gross-macroscopic resection was achieved. Surgical reconstruction of the skull base comprised of a fat graft, fascia lata overlay, and dural sealant. Given the extensive nasal involvement by the tumor, a vascularized nasoseptal flap was not feasible. The patient had an unremarkable postoperative course. She underwent intensity-modulated radiation therapy (IMRT) radiotherapy 6 weeks later, and was seen in follow-up 6 months later, with no issues. The link to the video can be found at: https://youtu.be/4bnsEUtieAw.
\end{abstract}

Conflicts of Interest None declared.

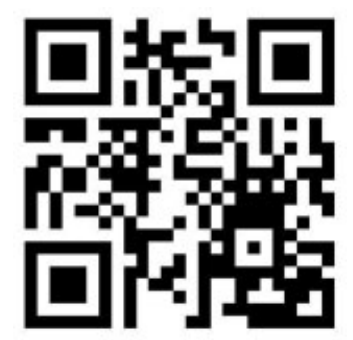

received

February 16, 2019 accepted after revision August 25, 2019 published online November 4, 2019

www.thieme.com/skullbasevideos

www.thieme.com/jnlsbvideos

DOI https://doi.org/

10.1055/s-0039-1700891. ISSN 2193-6331.
๑) 2019 Georg Thieme Verlag KG
Stuttgart · New York

License terms

(c) (1) $\odot \circledast$ 